\title{
SOIL MOISTURE RETRIEVAL USING GNSS-R DATA
}

\author{
Mehrez Zribi ${ }^{1}$, Mireille Huc ${ }^{1}$, Thierry Pellarin ${ }^{2}$, Nicolas Baghdadi ${ }^{3}$, and Nazzareno Pierdicca ${ }^{4}$ \\ ${ }^{1}$ CESBIO (CNRS/UPS/IRD/CNES), 18 av. Edouard Belin, bpi 2801, 31401 Toulouse cedex 9, France \\ ${ }^{2}$ IGE; 38400 Saint-Martin-d'Hères, Grenoble \\ ${ }^{3}$ IRSTEA, University of Montpellier, UMR TETIS, 34093 Montpellier CEDEX 5, France \\ ${ }^{4}$ Department of Information Engineering, Electronics, Telecommunications, Sapienza University of \\ Rome, Via Eudossiana 18, 00184 Rome, Italy
}

\begin{abstract}
The aim of this study is to propose an inversion algorithm for CYGNSS constellation data, which can be used for the monitoring of soil moisture. A change detection approach based on a 21-month CYGNSS data time series is proposed, and is processed to retrieve daily average reflectivity over a grid with a spatial resolution equal to $0.5^{\circ} \times 0.5^{\circ}$. Auxiliary data, including PROBA-V optical measurements and SRTM Digital Terrain Model products are used to account for the influence of vegetation and relief. The proposed estimates are validated at three different African sites (Merguellil, Tunisia; Basso Dallo, Niger; and Ouémé, Benin), using field moisture measurements acquired at $5 \mathrm{~cm}$ soil depth.
\end{abstract}

Keywords: CYGNSS, GNSS-R, soil moisture, change detection

\section{INTRODUCTION}

Soil moisture is a key state parameter, related to the land surface, and influences the manner in which rainwater is shared between evapotranspiration, infiltration, and runoff [1-3]. In the case of semi-arid regions, it is crucial for irrigation management and drought monitoring. Considerable efforts have thus been devoted to improve the evaluation of soil moisture and evapotranspiration, and to understand their relationship with the vegetation cover and soil water content. Most of this research has been based on remote sensing, which is highly convenient for the estimation of spatio -temporal variations in soil moisture.

Over the last 20 years, microwave remote sensing has convincingly demonstrated its ability to enable the monitoring of soil moisture. Through the use of radiometers, scatterometers and Synthetic Aperture Radars (SARs), the soil moisture can be monitored at various spatial resolutions, ranging from local field scales to approximately $50 \mathrm{~km}$. More recently, the use of GNSS reflectometry (GNSS-R) has become a mature technique for the remote sensing of land surfaces [4-10] With several spaceborne missions, including the Techdemosat-1 demonstrator, and the recently launched dedicated CYGNSS constellation [11], currently flying and able to measure GNSS-R signals reflected by the Earth's Surface, the field is currently opening up to the systematic use of global observations [12-15].
With the advent of these new satellite missions, combined with a detailed understanding of their technical and scientific capabilities, the present study proposes an inversion algorithm for the retrieval of surface soil moisture, based on surface reflectivity derived from CYGNSS data. Section 2 describes the satellite data, the study sites, the database used for ground validation and the retrieval methodology. Section 3 describes the results and the validation of soil moisture products. These results are discussed in section 4 , and our conclusions are presented in section 5 .

\section{DATABASE AND METHODS}

\subsection{Studied sites and ground measurements}

In the following, three local sites are considered for more detailed analyses, and the verification of soil moisture estimations derived from CYGNSS signals (Figure 1) by comparison with in-situ data. As these sites are located in three climatically different regions, our analysis of the data has allowed the quality and limitations of moisture estimations to be discussed.

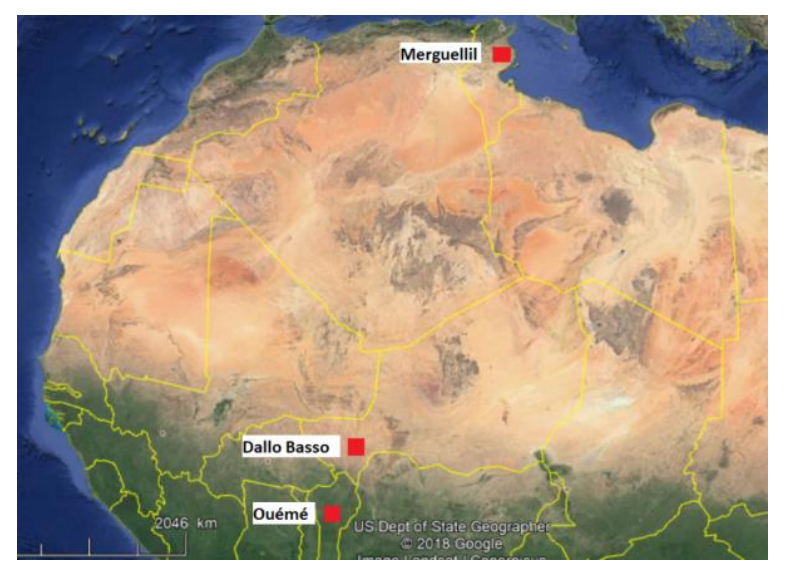

Figure 1. Illustration of the three studied sites (Merguellil, Dallo Basso and Ouémé)

\subsection{CYGNSS data}


NASA's CYGNSS constellation of eight satellites was launched in December 2016, and was designed to measure GNSS reflectivity over the tropics, at latitudes ranging between $\pm 37^{\circ}$, with the main purpose to measure wind in tropical cyclones. A land reflectivity observable $\Gamma$ is derived from the peak value of the L1 DDMs, to which a calibration factor is applied. The latter is computed using the radar equation for a coherent signal, such that the received power reflected by a surface $\operatorname{Prs}$ is given by:

$$
\text { Prs }=\operatorname{Pr}-N=\Gamma(\theta) \frac{\lambda^{2} G t G r P t}{(4 \pi)^{2}(R r+R t)^{2}}
$$

where $P r$ is the peak value of the L1 DDM power, $N$ is the estimated noise floor, $P t$ is the transmitted power, $G t$ and $G r$ are the transmitter and receiver antenna gains, respectively, and $R t$ and $R r$ are the distances between the transmitter and the specular point, and between the receiver and the specular point, respectively. By inverting (1), the reflectivity can thus be computed as:

$$
\Gamma(\theta)=\frac{(4 \pi)^{2}(P r-N)(R r+R t)^{2}}{\lambda^{2} G t P t G r}
$$

All of the parameters in this expression can be retrieved from the CYGNSS NetCDF files.

In the case of a smooth reflecting surface, the theoretical footprint of a reflected GNSS signal is determined by the first Fresnel zone, corresponding to approximately $0.5 \times 0.5$ $\mathrm{km}$ in the case of a spaceborne receiver.

\subsection{Proposed inversion approach}

Five processing steps were implemented, prior to application of the inversion algorithm:

Step1: In order to eliminate noisy measurements, which would lead to a high uncertainty in the reflectivity estimations, the data were filtered by retaining only these measurements having a high Signal-to-Noise-Ratio (SNR >3 $\mathrm{dB})$. In addition, only data recorded at incidence angles lower than $35^{\circ}$ were considered, since a strong decrease in SNR was encountered with measurements recorded at higher angles.

Step2: The CYGNSS datapoints were then restricted to measurements for which the corresponding NDVI (estimated from PROBA-V data) lay between 0.1 and 0.8 . The aim of this filter was to discard water bodies (low NDVI), which can generate soil moisture estimations with high errors, due to the very high reflectivity of flat specular water surfaces, as well as dense forests (very high NDVI), for which soil moisture estimations are often unreliable, as a consequence of the limited penetration of electromagnetic waves.

Step3: The nature of the local terrain can have a very strong influence on GNSS-R reflectivity, leading to inaccurate soil moisture estimations. For this reason, only data recorded over low altitude areas were considered, by applying a cutoff at threshold of $600 \mathrm{~m}$ as taken by Chew et al., 2018 [14]. Step 4: The CYGNSS measurements retained, after the filtering described in steps 1, 2 and 3, was then normalized to a reference incidence angle equal to $20^{\circ}$, using locally a simple linear correction.

Step 5: The CYGNSS observations were aggregated over a grid with $0.5^{\circ} \times 0.5^{\circ}$ pixel size, by averaging data over a daily interval. It must be noted that the spatio-temporal sampling of the available database has some limitations. On any given day, only a part of each $0.5^{\circ} \times 0.5^{\circ}$ pixel is covered by CYGNSS reflectivity measurements, and this partial coverage varies from one day to the next one.

Figure 2 provides a low-resolution $\left(0.5 \times 0.5^{\circ}\right.$ grid $)$ reflectivity map of West Africa, computed for the month of March, 2017. This is a dry month, during which the soil moisture in the studied region is very low, and has virtually no influence on ground reflectivity. The highest values are retrieved in regions with flat surfaces and almost no vegetation cover, in the north of the studied region associated, a priori, with a high coherent component of the scattered signal.

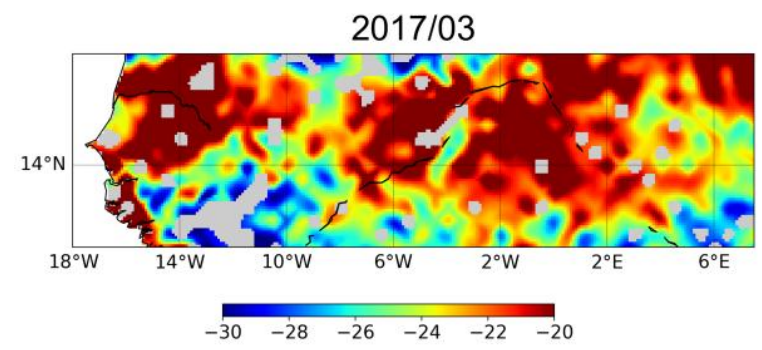

Figure 2. Reflectivity map of West Africa, computed from CYGNSS data recorded in March 2017

A change detection algorithm is applied to the data over a $0.5^{\circ} \times 0.5^{\circ}$ grid, allowing the soil moisture to be determined for the full duration of the study (about 21 months). It is assumed that the highest value of reflectivity (Гmax) corresponds to the highest level of observed soil moisture, and that the lowest value ( Гmin) corresponds to the driest conditions. As this study makes use of a large database, we make the assumption that Гmax corresponds to soil saturation and Гmin corresponds to the driest possible conditions. An index ranging between 0 and $100 \%$ is then estimated, according to expression (4), which we hereafter refer to as the soil moisture index (Ind). In the case of the ASCAT moisture products, $0 \%$ corresponds to the driest soil (very low soil moisture, close to 0 vol. $\%$ at the studied sites), and $100 \%$ corresponds to the wettest conditions (generally considered to correspond to soil saturation).

$$
\text { Ind }=\frac{\Gamma-\Gamma_{\min }}{\Gamma_{\max }-\Gamma_{\min }} \times 100
$$

\section{RESULTS AND DISCUSSIONS}


In Figure 3 we compare the ground measurements with the GNSS-R products for the three study areas in Tunisia, Niger and Benin, showing that the surface soil moisture (at a depth of $5 \mathrm{~cm}$ ) derived from the GNSS-R data is well correlated with the in situ measurements. For these three sites, the GNSS-R products are found to track the temporal dynamics of soil moisture with a good accuracy during the rainy season. During the dry season, the CYGNSS data are highly variable, despite the absence of temporal and/or spatial variations in soil moisture. This could be due to uncertainties in the retrieval of low values of reflectivity, and to surface heterogeneities at the $0.5^{\circ} \times 0.5^{\circ}$ grid scale. The satellite products converted in volumetric moisture are found to be only moderately correlated with the groundtruth measurements: the RMSE is equal to 6.7 vol.\%, 1.8 vol.\% and 5.1 vol.\% respectively, for the Merguellil, Basso Dallo and Ouémé areas. When the dry period is excluded from the proposed comparison, the results improve and are characterized by more accurate soil moisture estimations.
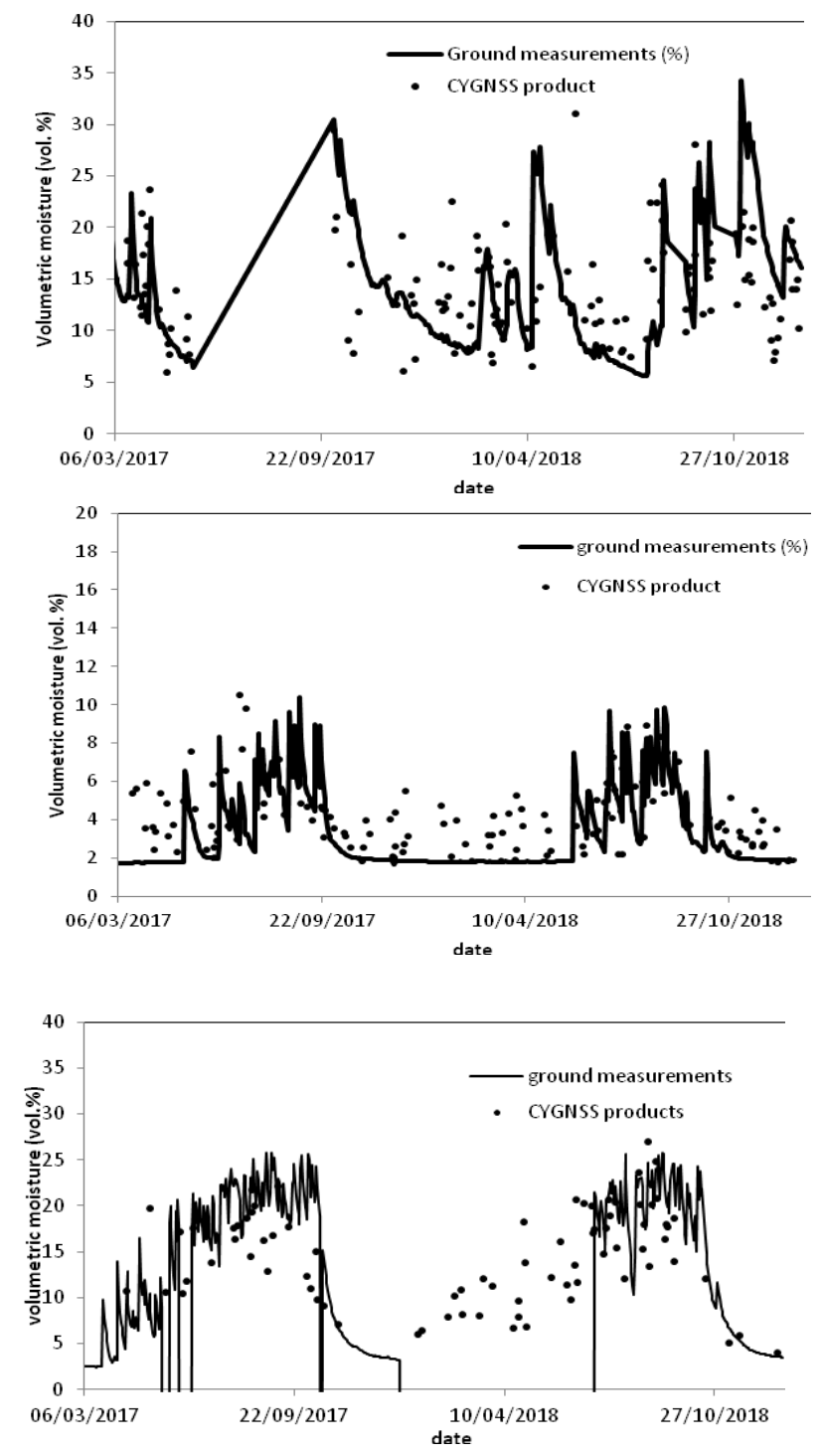

Figure 3. Comparison between CYGNSS moisture products and ground measurements. Upper panel: Merguellil site mid panel:

Dallo Basso site; lower panel: Ouémé site

\section{CONCLUSIONS}

The aim of this study is to develop an inversion algorithm for the estimation of surface soil moisture. CYGNSS data were processed and combined with other auxiliary satellite products from PROBA-V, and a DTM from SRTM. A change detection method was then applied to the daily reflectivity product, tuned on a 21-month sequence of CYGNSS acquisitions, leading to a calibrated soil moisture index ranging between 0 and 100 . The proposed methodology has been validated by comparing the CYGNSS product with ground measurements, recorded at three different sites (Merguellil, Basso Dallo and Ouémé), leading to an RMSE equal to 6.7 vol.\%, 1.8 vol.\% and 5.1 vol.\%, respectively.

\section{REFERENCES}

[1] Koster, R.D.; Dirmeyer, P.A.; Guo, Z.; Bonan, G.; Chan, E.; Cox, P.; Gordon, C.T.; Kanae, S.; Kowalczyk, E.; Lawrence, D.; Liu, P.; Lu, C.-H.; Malyshev, S.; McAvaney, B.; Mitchell, K.; Mocko, D.; Oki, T.; Oleson, K.; Pitman, A.; Sud, Y.C.; Taylor, C.M.; Verseghy, D.; Vasic, R.; Xue, Y.; Yamada, T. Regions of Strong Coupling Between Soil Moisture and Precipitation. Science. 2004, 305, 1138-1140. doi:10.1126/science.1100217

[2] Saux-Picart, S.; Ottlé, C.; Decharme, B.; André, C.; Zribi, M.; Perrier, A.; Coudert, B.; Boulain, N.; Cappelaere, B. Water and Energy budgets simulation over the Niger super site spatially constrained with remote sensing data, Journal of Hdrology, 2009, 375, 287-295.

[3] Gao, Q.; Zribi, M.; Escorihuela, M.; Baghdadi, N.; Segui, P. Irrigation Mapping Using Sentinel-1 Time Series at Field Scale. Remote Sens. 2018, 10, 9, 1495.

[4] Egido, A.; Paloscia, S.; Motte, E.; Guerriero, L.; Pierdicca, N.; Caparrini, M.; Santi, E.; Fontanelli, G.; Floury, N. Airborne GNSS-R Polarimetric Measurements for Soil Moisture and Above-Ground Biomass Estimation. IEEE J. Sel. Top. Appl. Earth Obs. Remote Sens. 2014, 7, 1522-1532. doi:10.1109/JSTARS.2014.2322854.

[5] C. S. Ruf, C. Chew, T. Lang, M.G. Morris, K. Nave, A. Ridley, R. Balasubramaniam, "A New Paradigm in Earth Environmental Monitoring with the CYGNSS Small Satellite Constellation," Scientific Reports, doi: 10.1038/s41598-01827127-4, 2018

[6] Katzberg, S.J.; Torres, O.; Grant, M.S.; Masters, D. Utilizing calibrated GPS reflected signals to estimate soil reflectivity and dielectric constant: Results from SMEX02. Remote Sens. Environ. 2006, 100, 17-28. doi:10.1016/j.rse.2005.09.015

[7] Masters, D.; Axelrad, P.; Katzberg, S. Initial results of landreflected GPS bistatic radar measurements in SMEX02, in: 
Remote Sensing of Environment. 2004, 507-520. doi:10.1016/j.rse.2004.05.016

[8] Sánchez, N.; Alonso-Arroyo, A.; Martínez-Fernández, J.; Piles, M.; González-Zamora, A.; Camps, A.; and Vall-llosera, M. On the Synergy of Airborne GNSS-R and Landsat 8 for Soil Moisture Estimation, Remote Sensing. 2015, 7, 9954-9974.

[9] Zribi, M.; Motte, E.; Baghdadi, N.; Baup, F.; Dayau, S.; Fanise, P.; Guyon, D.; Potential Applications of GNSS-R Observations over Agricultural Areas: Results from the GLORI Airborne Campaign, Remote Sensing 10 (8), 1245.

[10] Motte, E.; Zribi, M.; Fanise, P.; Egido, A.; Darrozes, J.; AlYaari, A.; Baghdadi, N.; Baup, F.; Dayau, S.; Fieuzal, R.; Frison, P.-L.; Guyon, D.; Wigneron, J.-P. GLORI: A GNSSR Dual Polarization Airborne Instrument for Land Surface Monitoring. Sensors. 2016, 16, 732. doi:10.3390/s16050732.

[11] C.Ruf et al.,"New ocean winds satellite mission to probe hurricanes and tropical convection," Bull. Amer. Meteorol. Soc., vol. 97, pp. 385-395, 2016. doi: 10.1175/BAMS-D-1400218.1.

[12] Camps A., M. Vall-llossera, H. Park, G. Portal, and L. Rossato, "Sensitivity of TDS-1 GNSS-R Reflectivity to Soil Moisture: Global and Regional Differences and Impact of Different Spatial Scales. Remote Sens. 2018, 10, 1856. doi: $10.3390 /$ rs 10111856

[13] Chew, C.; Shah, R.; Zuffada, C.; Hajj, G.; Masters, D.; Mannucci, A.J. Demonstrating soil moisture remote sensing with observations from the UK TechDemoSat-1 satellite mission. Geophys. Res. Lett. 2016, doi:10.1002/2016GL068189.

[14] Chew, C. C.; Small, E. E.; Soil Moisture Sensing Using Spaceborne GNSS Reflections: Comparison of CYGNSS Reflectivity to SMAP Soil Moisture, Geophys. Res. Lett. 2018, https://doi.org/10.1029/2018GL077905

[15] Clarizia, M.P. \& Pierdicca, Nazzareno \& Costantini, Fabiano \& Floury, Nicolas. (2019). Analysis of CYGNSS Data for Soil Moisture Retrieval. IEEE Journal of Selected Topics in Applied Earth Observations and Remote Sensing. PP. 1-9. 10.1109/JSTARS.2019.2895510. 